\title{
DIFFERENTIAL REGULATION OF ACETYLCHOLINE SENSITIVITY AND $\alpha$-BUNGAROTOXIN-BINDING SITES ON CILIARY GANGLION NEURONS IN CELL CULTURE ${ }^{1}$
}

\author{
MARTIN A. SMITH, JOSEPH F. MARGIOTTA, AND DARWIN K. BERG ${ }^{2}$ \\ Department of Biology, University of California, San Diego, La Jolla, California 92093
}

Received April 22, 1983; Accepted June 29, 1983

\begin{abstract}
Levels of acetylcholine (ACh) sensitivity and numbers of $\alpha$-bungarotoxin ( $\alpha$-Bgt)-binding sites have been measured for chick ciliary ganglion neurons grown in cell culture under various conditions. The two properties were found not to change in parallel. Neurons maintained in culture medium supplemented with embryonic eye extract developed high levels of ACh sensitivity and low numbers of $\alpha$-Bgt-binding sites, whereas neurons grown in medium containing elevated $\mathrm{K}^{+}$concentrations displayed the reverse. Neurons from media containing both eye extract and elevated $\mathrm{K}^{+}$concentrations had both low levels of sensitivity and low numbers of toxin sites. The growth conditions do not alter the basic binding properties of the ACh receptors and $\alpha$-Bgt-binding sites. Both the ACh receptor dose-response characteristics and the pharmacological properties of the toxin-binding sites were similar for neurons grown in media containing eye extract or elevated $\mathrm{K}^{+}$concentrations. The inhibitory effects of eye extract on development of $\alpha$-Bgt-binding sites appeared to be specific: eye extract had previously been shown to stimulate neuronal growth and cholinergic development, and in the present study eye extract enhanced development of ACh sensitivity and had no effect on mechanisms responsible for binding and accumulation of tetanus toxin. Eye extract did not block $\alpha$-Bgt binding in competition binding experiments and did not cause redistribution of toxin sites away from the neuronal soma. These results demonstrate that ACh sensitivity and $\alpha$-Bgt-binding sites can be independently regulated on the neurons and suggest that the two membrane properties are associated with separate membrane components.
\end{abstract}

Many populations of central and peripheral neurons that have nicotinic acetylcholine (ACh) receptors also possess high affinity binding sites for $\alpha$-bungarotoxin $(\alpha$ Bgt). Based on the distribution, kinetics, and pharmacology of binding, $\alpha$-Bgt has been advanced as a putative ligand for the neuronal ACh receptor (for reviews see Morley and Kemp, 1981; Oswald and Freeman, 1981). Although it is well documented that $\alpha$-Bgt binds to ACh receptors in vertebrate skeletal muscle and electric tissue (for review see Fambrough, 1979), the relationship of the toxin-binding site to the ACh receptor on neurons re-

\footnotetext{
${ }^{1}$ We thank Dr. Nicholas C. Spitzer for comments on the manuscript, Marie Ryder for expert technical assistance throughout the course of this work, and Al Franco for skilled assistance with preparation of the figures. Grant support was provided by the National Institutes of Health (NS 12601), the Muscular Dystrophy Association, and the American Heart Association with funds contributed in part by the California Heart Association. M. A. S. is a Muscular Dystrophy $\Lambda$ sso ciation postdoctoral fellow, and J. F. M. is a National Research Service postdoctoral fellow.

${ }^{2}$ To whom correspondence should be addressed.
}

mains controversial. Although exceptions have been reported (Marshall, 1981; Syapin et al., 1982), it has generally been found that $\alpha$-Bgt does not block ACh receptor function on neurons (Nurse and O'Lague, 1975; Duggan et al., 1976; Ko et al., 1976; Brown and Fumagalli, 1977; Bursztajn and Gershon, 1977; Patrick and Stallcup, 1977a; Carbonetto et al., 1978; Kouvelas et al., 1978; Ascher et al., 1979; Betz, 1981). Moreover, immunological studies have indicated that antibodies that block $\mathrm{ACh}$ receptor function on the pheochromocytoma cell line PC12 do not recognize the membrane component responsible for binding $\alpha$-Bgt on the same cells (Patrick and Stallcup, 1977b).

The chick ciliary ganglion is a useful system for studying the regulation of neuronal ACh receptors and examining the relationship between the receptors and $\alpha$-Bgtbinding sites. The neurons elaborate nicotinic $\mathrm{ACh}$ receptors which mediate the only known form of chemical synaptic transmission through the ganglion (Martin and Pilar, 1963a, b; Landmesser and Pilar, 1978). The neurons also develop large numbers of high affinity $\alpha$-Bgt- 
binding sites, but concentrations of $\alpha$-Bgt sufficient to saturate the sites have no detectable effect on the excitatory, nicotinic $\mathrm{ACh}$ response of the neurons (Ravdin and Berg, 1979; Chiappinelli et al., 1981; Ravdin et al., 1981; Margiotta and Berg, 1982). Furthermore, recent ultrastructural studies using horseradish peroxidase-conjugated $\alpha$-Bgt demonstrate that, although toxin-binding sites are localized on the ganglionic neuron membrane primarily in regions contacted by preganglionic terminals, the sites appear to be excluded from the immediate postsynaptic membrane (Jacob and Berg, 1983). These results suggest that the toxin-binding sites on ciliary ganglion neurons are different from synaptic $\mathrm{ACh}$ receptors on the cells. Accordingly, it seemed possible that the toxin-binding sites and $\mathrm{ACh}$ receptors could be subject to different regulatory controls.

To investigate this possibility we examined the development of ACh receptors and $\alpha$-Bgt-binding sites on ciliary ganglion neurons maintained in cell culture under growth conditions previously shown to support complete survival but to alter cytoplasmic growth and development of the neurons (Nishi and Berg, 1981a, b). The results indicate that the two membrane properties, $\mathrm{ACh}$ sensitivity and $\alpha$-Bgt binding, can be independently regulated in culture. A preliminary account of this work has appeared (Smith et al., 1982).

\section{Materials and Methods}

Cell cultures. Ciliary ganglia from 8-day chick embryos were dissociated and grown in cell culture on a substratum of collagen and lysed fibroblasts as previously described (Nishi and Berg, 1981a). Cultures contained 1 to $2 \times 10^{4}$ neurons either in 35-mm dishes for electrophysiological and autoradiographic studies, or in $16-\mathrm{mm}$ wells for toxin-binding experiments. Culture medium consisted of Eagle's minimal essential medium (MEM) containing $10 \%(\mathrm{v} / \mathrm{v})$ heat-inactivated horse serum, 50 units $/ \mathrm{ml}$ of penicillin, and $50 \mu \mathrm{g} / \mathrm{ml}$ of streptomycin. Media supplements included either embryonic chick eye extract ( $3 \% \mathrm{v} / \mathrm{v}$; "eye medium"), $\mathrm{KCl}(25 \mathrm{~mm}$ final concentrations; " $\mathrm{K}^{+}$medium"), or both (" $\mathrm{K}^{+} /$eye medium") as previously described (Nishi and Berg, 1981a). The culture medium was replaced with fresh medium at $2-$ to 3 -day intervals.

Electrophysiology. Neuronal ACh sensitivities were determined using intracellular recording techniques to measure the change in membrane conductance caused by a brief pulse of $\mathrm{ACh}$ pressure ejected from a nearby micropipette (Choi and Fischbach, 1981). Recordings were obtained from neurons maintained at $37^{\circ} \mathrm{C}$ on the stage of an inverted microscope (O'Lague et al., 1978; Margiotta and Berg, 1982). Cells were continuously perfused with MEM modified to contain $5.4 \mathrm{mM} \mathrm{Ca}^{2+}, 5.4$ $\mathrm{mM} \mathrm{K}^{\prime}$, and $2 \mathrm{mM}$ HEPES buffer to replace the bicarbonate buffer, and supplemented with $10 \%(\mathrm{v} / \mathrm{v})$ horse serum. Micropipettes used for applying $\mathrm{ACh}$ to the neurons had tip diameters of 5 to $10 \mu \mathrm{m}$ and were filled with known concentrations of ACh $(1 \mu \mathrm{M}$ to $50 \mathrm{mM})$ in a balanced salt solution (Dichter and Fischbach, 1977). Brief pulses of air pressure ( 2 to 8 psi for 1 to $3 \mathrm{sec}$ ) were used to eject $\mathrm{ACh}$ from the micropipette after positioning it about 15 to $30 \mu \mathrm{m}$ from the neuron soma. Experiments with $\mathrm{K}^{+}$- and dye-filled micropipettes indicated that the procedure completely immerses the soma in the ejected solution (Choi and Fischbach, 1981; J. F. Margiotta, unpublished observations). ACh sensitivities determined with this approach probably reflect a "summed" response from most of the soma ACh receptors. Input conductances were measured using a single intracellular electrode in conjunction with an amplifier and a Wheatstone bridge circuit (W. P. Instruments, M701): constant inward current pulses of 0.05 to $0.20 \mathrm{nA}$ amplitude and 50 msec duration were passed through the neuron, and the resulting membrane hyperpolarizations were recorded before and during ACh exposure. The ACh-induced conductance was calculated as the difference between the maximum input conductance measured in the presence of $\mathrm{ACh}$ and the resting input conductance prior to the application of ACh. In some cases neurons were penetrated with two microelectrodes, one for passing current and a second for recording membrane voltage changes. ACh-induced conductances measured in this way were in close agreement with those obtained in single electrode experiments.

Using conductance changes instead of potential changes to assess ACh sensitivities takes into account differences in resting input conductance among neurons and also renders the results independent of the reversal potential. In some cases, however, the application of ACh caused a large depolarization, necessitating small corrections for contributions from voltage-dependent ionic conductances. Such corrections were minimized by using subsaturating concentrations of ACh $(0.1 \mathrm{mM})$ for the standard test condition and routinely adjusting the starting resting potential to about $-80 \mathrm{mV}$. With these conditions most neurons did not depolarize more than 30 $\mathrm{mV}$, i.e., to a membrane potential of about $-50 \mathrm{mV}$, during ACh application. The current-voltage relationship for neurons grown in eye medium was linear when applied currents produced deporalization of up to $29.0 \pm$ $3.0 \mathrm{mV}$ (mean $\pm \mathrm{SE}, n=5$ neurons). Beyond this level of depolarization, the slope conductance of the neurons increased, and appropriate corrections were applied. Under standard test conditions none of the measurements obtained with neurons from $\mathrm{K}^{+}$medium required correction, whereas about half of those for neurons from eye medium did so. Data were accepted only in those cases where the neuron was capable of firing overshooting action potentials in response to intracellular stimulation, where resting potentials were more negative than -50 $\mathrm{mV}$ (without adjustment) before and after the test pulse of $\mathrm{ACh}$, and where the recording electrode was out of balance by no more than $3 \mathrm{mV}$ when withdrawn from the neuron at the end of the experiment and corrections for the imbalance could be made.

$\alpha$-Bgt binding studies. $\alpha$-Bgt was purified from the venom of Bungarus multicinctus as previously described (Ravdin and Berg, 1979). [ $\left.{ }^{120} \mathrm{I}\right] \mathrm{Di}$-iodo- $\alpha$-Bgt was prepared and isolated with initial specific activities of 250 to $300 \mathrm{Ci} / \mathrm{mmol}$ according to the method of Vogel et al. (1972). Binding studies were carried out by first rinsing the cultures twice with MEM containing $10 \%(\mathrm{v} / \mathrm{v})$ horse 
serum and $5 \%(\mathrm{v} / \mathrm{v})$ embryo extract (binding medium), and then incubating the cultures in the binding medium containing $20 \mathrm{nM}\left[{ }^{125} \mathrm{I}\right] \mathrm{di}$-iodo- $\alpha$-Bgt for $1 \mathrm{hr}$ at $37^{\circ} \mathrm{C}$. These conditions were previously shown to saturate $\alpha$ Bgt-binding sites on the neurons (Ravdin et al., 1981). The cultures were rinsed four times over a 20 -min period with $1-\mathrm{ml}$ aliquots of $11 \mathrm{~mm}$ sodium phosphate buffer (pH 7.3) containing $123 \mathrm{mM} \mathrm{NaCl}, 5.4 \mathrm{mM} \mathrm{KCl}, 0.9 \mathrm{mM}$ $\mathrm{CaCl}_{2}, 0.4 \mathrm{mM} \mathrm{MgSO}{ }_{4}$ (rinse solution), with $2 \mathrm{mg} / \mathrm{ml}$ of bovine serum albumin and then were scraped in $0.5 \mathrm{ml}$ of $0.6 \mathrm{~N} \mathrm{NaOH}$ and counted for radioactivity in a Nuclear Chicago gamma counter. Nonspecific binding was determined by incubating the cultures in $2 \mu \mathrm{M}$ unlabeled $\alpha$ Bgt for $30 \mathrm{~min}$ before and during the incubation with labeled $\alpha$-Bgt. Nonspecific binding was typically less than $5 \%$ of the total binding observed and was subtracted accordingly. Competition binding studies with $d$-tubocurarine $(d-\mathrm{TC})$, carbamylcholine, and eye extract were carried out in a similar manner except that the competing ligand or agent was used in place of unlabeled $\alpha$-Bgt, and $\left[{ }^{125} \mathrm{I}\right]$ di-iodo- $\alpha$-Bgt was present at $10 \mathrm{nM}$ instead of 20 nM.

Autoradiography. Light microscopic autoradiography was carried out by labeling neuronal cultures with [ $\left.{ }^{125} \mathrm{I}\right]$ di-iodo- $\alpha$-Bgt and washing them as described above. The cultures were fixed with rinse solution containing $1 \%$ glutaraldehyde and $2 \%$ paraformaldehyde for $1 \mathrm{hr}$ at $20^{\circ} \mathrm{C}$. After rinsing thoroughly with distilled water, the cultures were air dried, coated with Kodak NTB-2 emulsion diluted 1:1 with distilled water, exposed for 5 to 10 days at $4^{\circ} \mathrm{C}$, and developed with Kodak D-19 developer for $2.5 \mathrm{~min}$ at $18^{\circ} \mathrm{C}$.

Tetanus tuxin. Tetanus toxin (TTox) was iodinated by the chloramine $\mathrm{T}$ method (Greenwood et al., 1963) to produce $\left[{ }^{125} \mathrm{I}\right] \mathrm{TT}$ Tox with an initial specific activity of 2.5 $\mu \mathrm{Ci} / \mu \mathrm{g}$. Binding studies were carried out as described above except that ${ }^{125}$ I]TTox was used instead of labeled $\alpha$-Bgt. Binding of $\left[{ }^{125} \mathrm{I}\right]$ TTox $(0.5 \mu \mathrm{g} / \mathrm{ml})$ to blank cultures, i.e., culture wells of lysed fibroblasts carried through the standard feeding regimen, was less than $5 \%$ of the total binding to neuronal cultures.

Materials. Culture media components were obtained from Grand Island Biological Co., and tissue extracts and culture media were prepared as previously described (Nishi and Berg, 1981a). Bungarus multicinctus venom was purchased from Miami Serpentarium, tetanus toxin (TTox) was a generous gift from Dr. R. 'Thompson of the Wellcome Foundation, $\mathrm{Na}^{125} \mathrm{I}$ was purchased from Amersham, Kodak NTB-2 emulsion was from Eastman Kodak, and $d$-tubocurarine ( $d$-TC), carbamylcholine, bovine serum albumin, glutaraldehyde, and paraformaldehyde were from Sigma Chemical Co.

\section{Results}

ACh sensitivity. Brief application of ACh typically produced a delayed, maintained depolarization in ciliary ganglion neurons that decayed to resting levels 2 to 20 sec after termination of the ACh pulse. The ACh-induced depolarization was accompanied by an increase in membrane conductance and voltage noise. Neurons grown for
7 days in eye medium were quite sensitive to $\mathrm{ACh}$ when examined in this manner (Fig. 1A) whereas neurons grown either in $\mathrm{K}^{+}$/eye or $\mathrm{K}^{+}$medium and subsequently examined in standard test medium were much less sensitive (Fig. 1, $B$ and $C$ ). Relative levels of ACh sensitivity were compared for the neurons by calculating the conductance increase caused in each case by a pulse of 0.1 $\mathrm{mM}$ ACh. Neurons grown for 7 days in eye medium were nearly 4 times as sensitive to $\mathrm{ACh}$ as were neurons grown in $\mathrm{K}^{+}$/eye medium, and 13 times as sensitive as neurons grown in $\mathrm{K}^{+}$medium (Fig. $2 A$ ).

As previously reported (Margiotta and Berg, 1982), ciliary ganglion neurons form functional cholinergic synapses with one another in cell culture. The highest levels of spontaneous synaptic activity were associated with neurons grown in eye medium. Thus, over $70 \%$ of 229 neurons examined from eye medium cultures displayed spontaneous synaptic potentials whereas only $3 \%$ of 32 neurons from $\mathrm{K}^{+}$/eye cultures and $4 \%$ of 137 neurons from $\mathrm{K}^{+}$cultures did so.

$\alpha$-Bgt binding. A different pattern emerged when the numbers of $\alpha$-Bgt-binding sites were compared for neurons from 7-day cultures. The highest values of toxin binding were obtained with neurons grown in $\mathrm{K}^{+}$medium, and the lowest values were obtained with neurons grown in eye and $\mathrm{K}^{+}$/eye media (Fig. $2 B$ ).

Development. Differences were observed in the relative levels of ACh sensitivity and $\alpha$-Bgt binding on the neu-

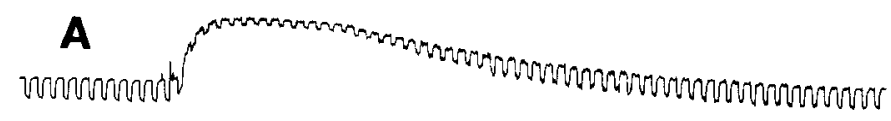

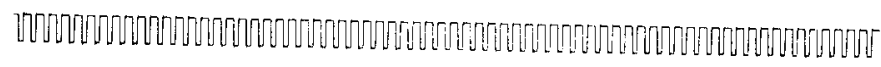

B

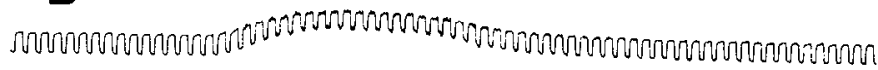

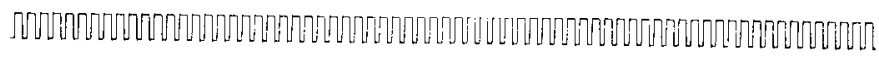

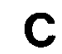

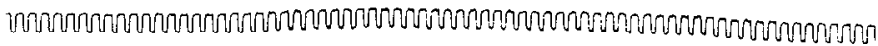

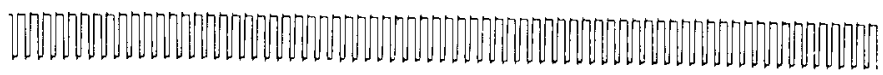

Figure 1. ACh conductance. Neurons grown for 7 days in eye $(A), \mathrm{K}^{+}$/eye $(B)$, and $\mathrm{K}^{+}$medium $(C)$ were tested (in standard recording medium) for responses to a pulse of $0.1 \mathrm{mM} \mathrm{ACh}$. In each case the upper trace indicates the membrane potential, the middle trace shows applied current, and the bottom trace (bar) marks the application of ACh. Calibration bars: vertical, $20 \mathrm{mV}$ and $0.1 \mathrm{nA}(A$ and $C)$ or $0.2 \mathrm{nA}(B)$; horizontal, $1 \mathrm{sec}$. 


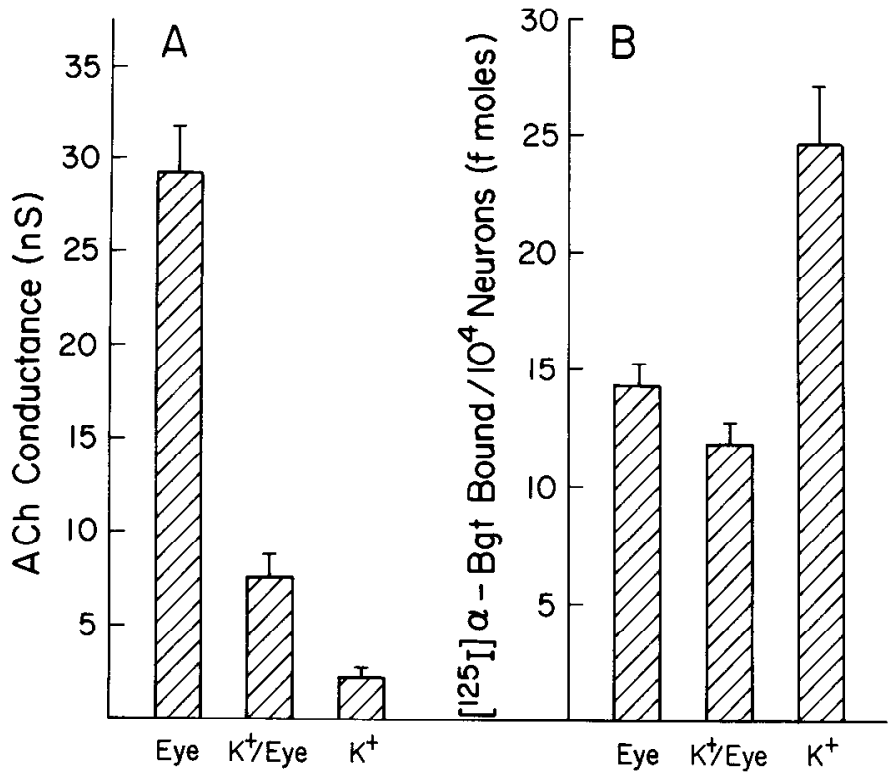

Culture Medium

Figure 2. Differences in ACh conductances and $\alpha$-Bgt binding levels. Neurons grown for 7 days in the indicated culture medium were tested for sensitivity to pulses of $0.1 \mathrm{mM} \mathrm{ACh}$ $(A)$ and for levels of $\alpha$-Bgt binding $(B)$. Results are expressed as the mean $\pm \mathrm{SE} ; n=12$ to 22 neurons from 3 to 6 experiments in $A$, and 24 to 36 cultures from 8 to 12 experiments in $B$.

rons throughout a 1-week test period. $\alpha$-Bgt-binding sites steadily increased in number with time in culture and, with the exception of neurons at 1 day, more sites were present on neurons grown in $\mathrm{K}^{+}$medium than in eye medium (Fig. 3A). In contrast, ACh sensitivities increased sharply over the first 3 days for neurons from eye medium and then remained constant for an additional 4 days; sensitivities for neurons from $\mathrm{K}^{+}$medium were low at all times tested (Fig. $3 B$ ).

Binding characteristics. The failure of ACh sensitivity and $\alpha$-Bgt binding to change in parallel during development cannot be explained by alterations in the affinity of the membrane components for their respective ligands. Varying the concentration of $\mathrm{ACh}$ in the test pulse produced dose-response curves that were similar for neurons grown in eye and $\mathrm{K}^{+}$media (Fig. 4). The curves have sigmoid shapes, reach maxima between 1 and 10 $\mathrm{mM} \mathrm{ACh}$, and indicate half-saturation at 0.1 to $0.5 \mathrm{mM}$ ACh. Large differences in sensitivities were also obtained when carbamylcholine $(0.5 \mathrm{mM})$ was used as the agonist instead of ACh: neurons from eye medium displayed carbamylcholine conductance changes of $27.6 \pm 8.1 \mathrm{nS}$ (mean $\pm \mathrm{SE} ; n=8$ ), and neurons from $\mathrm{K}^{+}$medium showed changes of $2.7 \pm 0.5 \mathrm{nS}(n=8)$.

The properties of $\alpha$-Bgt-binding sites on neurons grown in eye medium and $\mathrm{K}^{+}$medium also appeared to be similar. The toxin binding reflected the number of specific toxin sites since higher concentrations of $\left.{ }^{125} \mathrm{I}\right]$ di-iodo- $\alpha$-Bgt did not reveal additional binding (data not shown). $d$-TC and carbamylcholine, two inhibitors of toxin binding, blocked binding to the same extent on neurons from eye medium and from $\mathrm{K}^{+}$medium (Fig. 5).

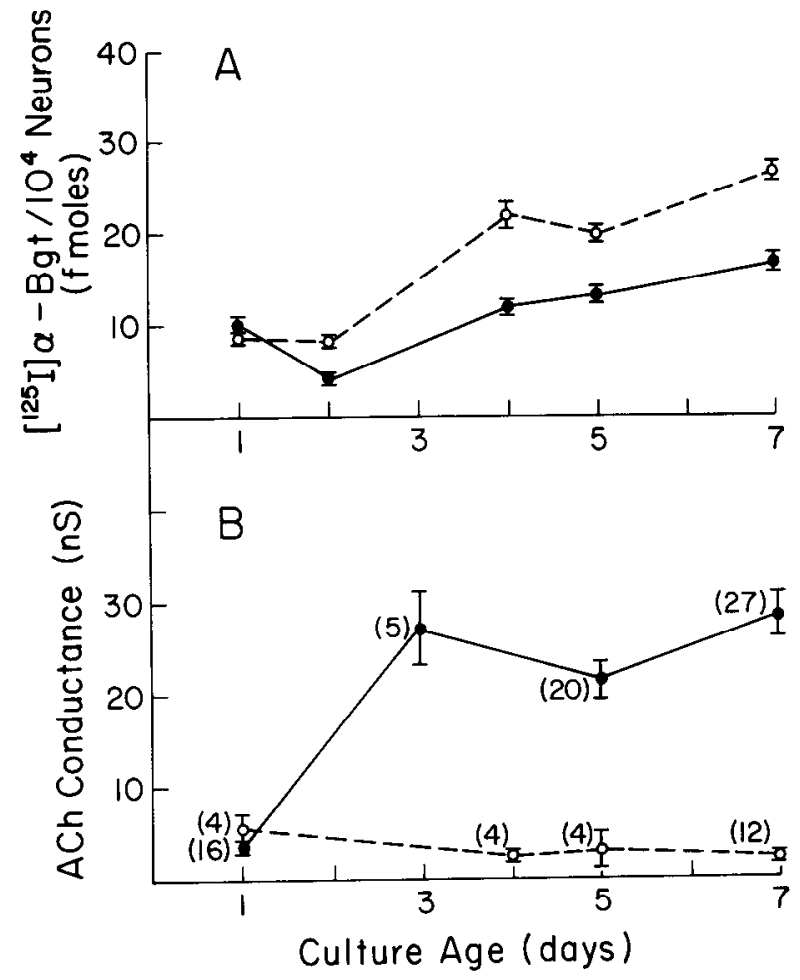

Figure 3. Development of $\alpha$-Bgt binding and ACh sensitivity. Neurons grown in eye medium (solid lines) and in $\mathrm{K}^{+}$medium (dashed lines) were tested for $\alpha$-Bgt binding $(A)$ and $\mathrm{ACh}$ sensitivity $(B)$ at the indicated times. The values represent the mean $\pm \mathrm{SE}$. In $A, n=15$ to 18 cultures (five to six experiments) for days 1,4 , and 7 , and 3 cultures (one experiment) for days 2 and 5 . In $B$, the numbers in parentheses indicate the number of neurons tested, a total of 21 cultures from 14 separate platings were used.

Distribution of $\alpha$-Bgt sites. The fact that levels of ACh sensitivity and $\alpha$-Bgt sites can vary independently on the neurons suggests that the toxin sites are not associated with the receptors responsible for ACh sensitivity. Alternatively, the results might be accounted for by maintaining that the toxin sites do represent $\mathrm{ACh}$ receptors but that the presence of eye extract in the culture medium promotes a radical redistribution of the sites/ receptors away from the cell soma. Since the sensitivity measurements reflect primarily soma receptors, a redistribution of the sites away from soma would score as reduced sensitivity without appearing as a reduction in the total number of sites per neuron. To test this possibility the distribution of $\left[{ }^{125} \mathrm{I}\right] \mathrm{di}$-iodo- $\alpha$-Bgt bound on the neurons was examined by light microscopic autoradiography. No evidence was found for a change in relative distribution. Substantially more labeling was associated with the somas of neurons grown in $\mathrm{K}^{+}$medium than with the somas of neurons grown in eye medium (Fig. 6), consistent with the values reported for the total sites per neuron in the two cases.

Effect of eye extract. Eye extract is known to promote growth and development of ciliary ganglion neurons in culture (Nishi and Berg, 1981a). Accordingly, it was surprising to find that eye extract retards the development of $\alpha$-Bgt-binding sites. We considered the possibil- 


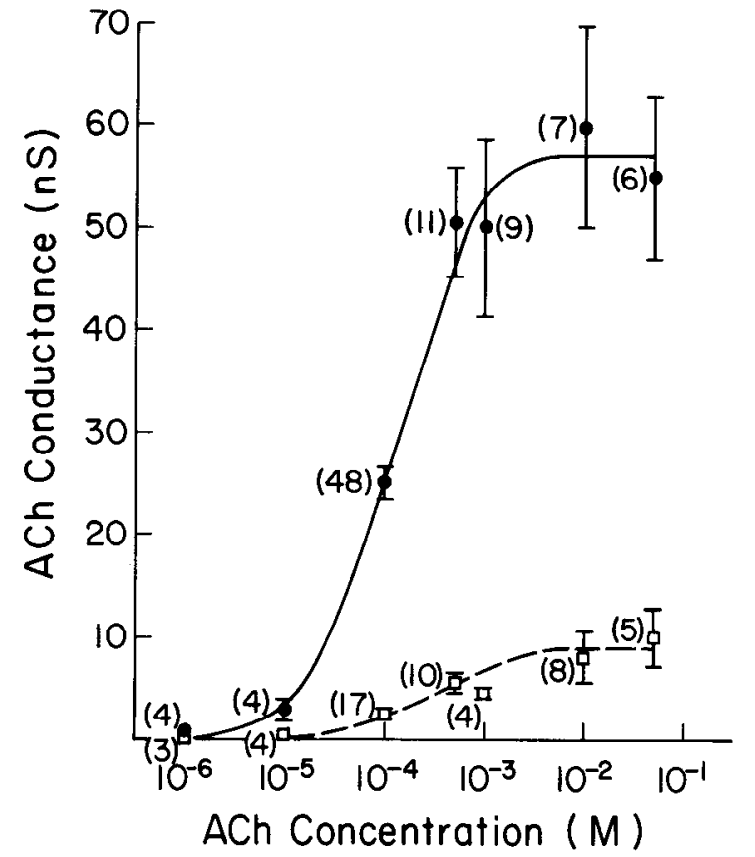

Figure 4. Dose-response curves for ACh sensitivity. Doseresponse curves were constructed for neurons grown 5 to 8 days in eye medium (solid line) and in $\mathrm{K}^{+}$medium (dashed line) by applying pulses of the indicated concentrations of $\mathrm{ACh}$ and measuring the ACh-induced conductance in each case. The values represent the mean $\pm \mathrm{SE}$. The numbers in parentheses indicate the number of neurons tested; a total of 40 cultures from 12 separate platings were used. A single concentration of $\mathrm{ACh}$ was tested on each neuron.

ity that eye extract contains a component that interferes acutely with $\alpha$-Bgt binding. To test this, competition binding experiments were carried out between eye extract and $\left[{ }^{125} \mathrm{I}\right]$ di-iodo- $\alpha$-Bgt on neurons grown in $\mathrm{K}^{+}$medium. No evidence for such a component was obtained. Neurons exposed to $0.3,1.0,3.0$, and $10 \%$ eye extract for 1 hr bound $105 \pm 4 \%, 112 \pm 3 \%, 103 \pm 3 \%$, and $100 \pm 4 \%$ (mean $\pm \mathrm{SE}, n=3$ cultures in each case) as much labeled toxin, respectively, as did neurons not exposed to eye extract. Similar results were obtained in a second experiment.

Chronic blockade of the $\alpha$-Bgt site did not protect it against regulation by the eye extract. Neurons grown for 7 days in $\mathrm{K}^{+}$medium containing $0.1 \mathrm{mM} d$-TC bound an equivalent amount of $\left.{ }^{[25} \mathrm{I}\right] \alpha-\mathrm{Bgt}$ to neurons grown in $\mathrm{K}^{+}$ medium lacking the drug. The levels of binding observed for neurons grown in $\mathrm{K}^{+}$/eye medium with or without $0.1 \mathrm{mM} d$-TC were each decreased about $35 \%$ compared to $\mathrm{K}^{+}$medium cultures ('Table I).

Tetanus toxin. It was of interest to determine whether eye extract influences other neuronal membrane components in a manner similar to that for $\alpha$-Bgt-binding sites. Tetanus toxin (TTox) is known to bind to neuronal gangliosides (for review see Mellanby and Green, 1981) and has been used as a cell surface marker for neurons in cell culture (Dimpfel et al., 1975; Mirsky et al., 1978). To compare the numbers of TTox-binding sites on neurons grown in eye and $\mathrm{K}^{+}$medium, the cultures were incubated with $\left[{ }^{125} \mathrm{I}\right] \mathrm{TT}$ Tox and the amount of neuron-

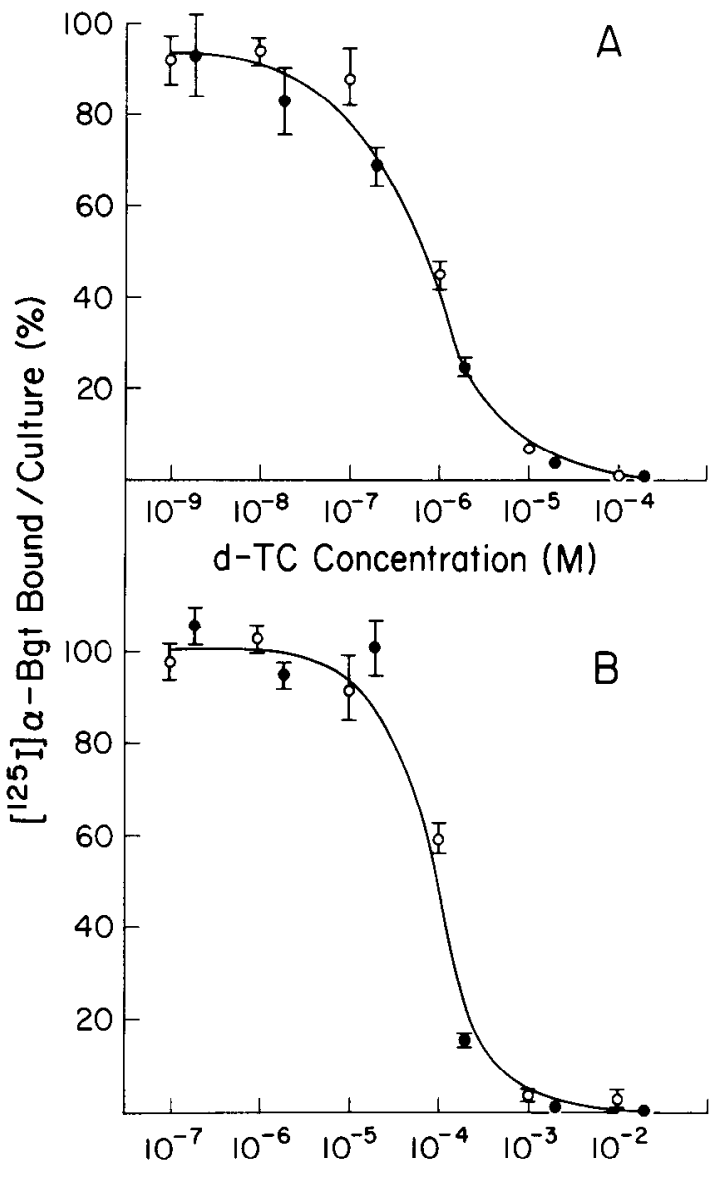

Carbamylcholine Concentration (M)

Figure 5. Pharmacology of $\alpha$-Bgt-binding sites. The sensitivity of $\alpha$-Bgt binding to competition from $d$-TC $(A)$ and carbamylcholine $(B)$ was tested for neurons grown 7 days in eye medium (solid circles) and $\mathrm{K}^{+}$medium (open circles). The results are expressed as a percentage of the specific binding obtained in the absence of competitor and in each case represents the mean $\pm \mathrm{SE}$ of six cultures from two separate experiments.

associated binding was determined. No difference in the level of TTox accumulation was found for the two neuronal populations over a 100 -fold concentration range of labeled TTox (Fig. 7). Over the concentration range used, accumulation of labeled TTox was not saturable. Much of the $\left.{ }^{125} \mathrm{I}\right] \mathrm{TT}$ Tox accumulation was specific, however, since cultures incubated with $100 \mu \mathrm{g} / \mathrm{ml}$ of unlabeled TTox for $30 \mathrm{~min}$ before and during the $1-\mathrm{hr}$ exposure to $0.5 \mu \mathrm{g} / \mathrm{ml}$ of $\left[{ }^{125} \mathrm{I}\right] \mathrm{TT}$ Tox accumulated only $34 \pm 2.5 \%$ (mean $\pm \mathrm{SF}, n=6$ cultures) as much radioactivity as cultures lacking the unlabeled TTox.

\section{Discussion}

The major finding reported here is that neuronal levels of ACh sensitivity do not correlate with $\alpha$-Bgt-binding sites. One set of growth conditions for the neurons led to development of high levels of ACh sensitivity and low levels of toxin binding, another set of growth conditions produced the reverse, and a third set resulted in low levels of both. The simplest explanation is that the $\alpha$ - 

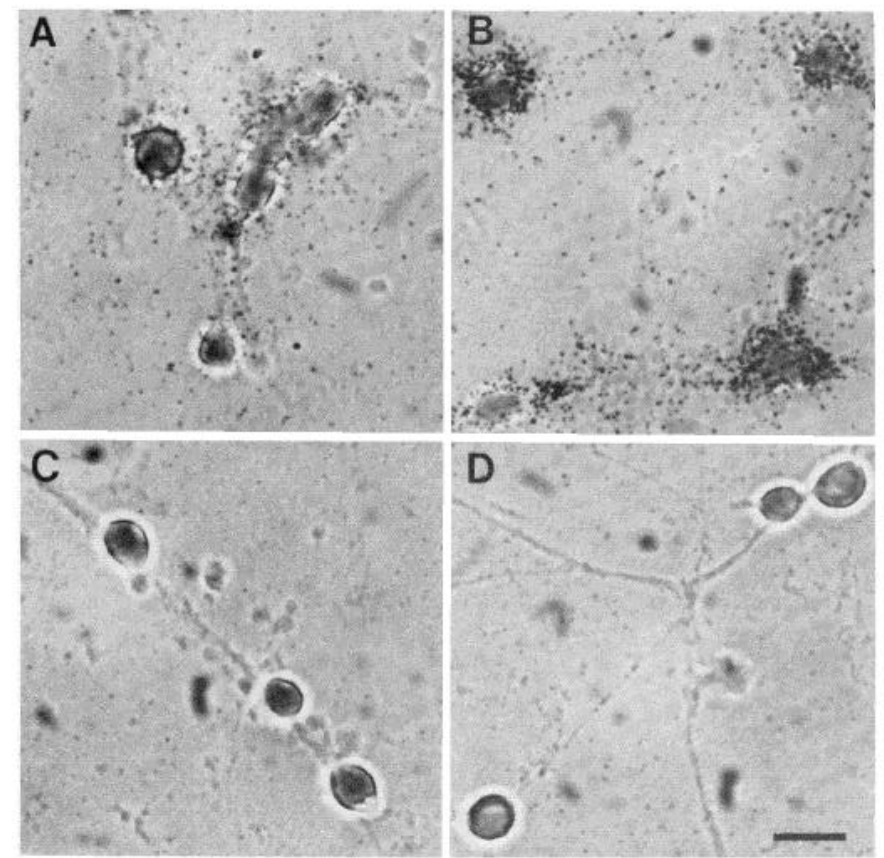

Figure 6. Distribution of $\alpha$-Bgt-binding sites. Neurons grown for 7 days in eye medium $\left(A\right.$ and $C$ ) and in $\mathrm{K}^{+}$medium $(B$ and $D$ ) were labeled either with $\left[{ }^{125} \mathrm{I}\right]$ di-iodo- $\alpha$-Bgt alone $(A$ and $B)$ or with [ $\left.{ }^{125} \mathrm{I}\right] \mathrm{di}$-iodo- $\alpha$-Bgt plus an excess of unlabeled $\alpha$-Bgt $(C$ and $D$ ) and exposed for autoradiography. Brightfield optics were used, and the focal plane was adjusted to reveal grains in the emulsion layer. Calibration bar, $20 \mu \mathrm{m}$.

TABLE I

Levels of $\alpha$-Bgt binding observed for neurons grown in culture medium with or without $d-T C$

Neurons were grown for 7 days in the indicated culture medium and $d$-TC concentration, and then rinsed and assayed for $\alpha$-Bgt binding. Values represent the mean $\pm \mathrm{SE}$ for six cultures from two separate experiments in each case.

\begin{tabular}{cccc}
\hline \multirow{2}{*}{ Growth Medium } & \multirow{2}{*}{$d$-TC } & \multicolumn{2}{c}{$\alpha$-Bgt Binding } \\
\cline { 3 - 4 } & & fmol/104 neurons & Percentage \\
\hline $\mathrm{K}^{+}$ & 0 & $21.4 \pm 2.0$ & 100 \\
$\mathrm{~K}^{+}$eye & 0 & $13.4 \pm 1.3$ & 63 \\
$\mathrm{~K}^{+}$ & $0.1 \mathrm{mM}$ & $19.7 \pm 1.9$ & 92 \\
$\mathrm{~K}^{+} /$eye & $0.1 \mathrm{mM}$ & $12.6 \pm 1.3$ & 59 \\
\hline
\end{tabular}

Bgt-binding sites do not represent $\mathrm{ACh}$ receptors responsible for the observed sensitivity, and the toxin-binding components and $\mathrm{ACh}$ receptors are subject to different forms of regulation. Such an explanation is consistent with recent results showing that the toxin sites appear to be present in extrasynaptic regions on the neurons but are absent from synaptic membrane (Jacob and Berg, 1983), in contrast to the expected distribution for synaptic $\mathrm{ACh}$ receptors.

Several trivial explanations for the lack of correlation between ACh sensitivity and $\alpha$-Bgt binding have been ruled out. These include demonstrating that the differences do not arise from changes in the binding properties of the toxin sites or from changes in the distribution of toxin sites in the neuronal membrane. Nor can the results be accounted for by changes in the affinity of the $\mathrm{ACh}$ receptor for its ligand or changes in the rate of

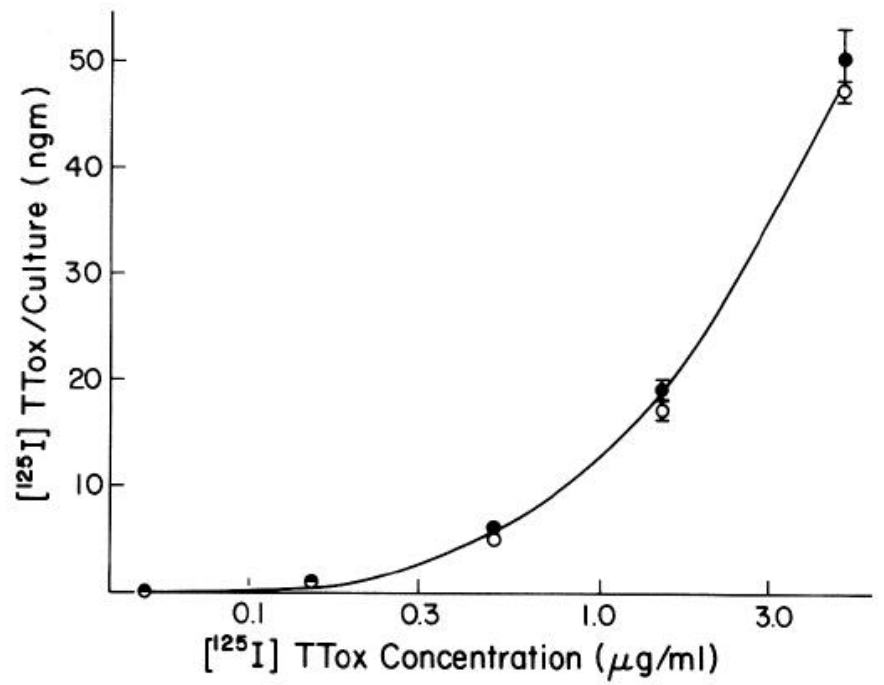

Figure 7. Binding of tetanus toxin. Neurons grown for 7 days in either eye medium (solid circles) or in $\mathrm{K}^{+}$medium (open circles) were tested for $\left[{ }^{125} \mathrm{I}\right] \mathrm{TT}$ Tox binding and accumulation. Values represent the mean $\pm \mathrm{SE}$ of three cultures in each case. Similar results were obtained in two additional experiments.

ligand hydrolysis in the cultures, since $\mathrm{ACh}$ and carbamylcholine produced the same effects. Differences in receptor desensitization seem unlikely to account for the different levels of sensitivity since $(a)$ the ACh doseresponse curves were similar for neurons from eye and $\mathrm{K}^{+}$media, $(b)$ the $\mathrm{ACh}$-induced conductances were sustained over time, and $(c)$ the incidence of spontaneous synaptic activity was much higher for neurons from eye medium than from $\mathrm{K}^{+}$medium, as expected if the former had greater numbers of $\mathrm{ACh}$ receptors.

The fact that $\mathrm{ACh}$ receptor number could not be measured directly for the neurons, however, leaves open the possibility that changes in levels of ACh sensitivity may reflect changes in receptor function rather than receptor number. Nicotinic ACh receptors in vertebrate skeletal muscle are known to undergo changes in mean channel open time during development in vivo (Sakmann and Brenner, 1978; Fischbach and Schuetze, 1980; Kullberg et al., 1981). Changes have also been reported in the single channel properties of muscle $\mathrm{ACh}$ receptors in culture (Brehm et al., 1982). There is no precedent, however, for changes in channel properties as large as the 13-fold difference reported here for levels of sensitivity associated with neurons grown in eye versus $\mathrm{K}^{+}$ medium. Even if chronic exposure to elevated $\mathrm{K}^{+}$concentrations did change $\mathrm{ACh}$ receptor function, this alone could not account for the pattern of nonparallel changes observed in levels of ACh sensitivity and $\alpha$-Bgt binding.

An alternative explanation for the effects of $\mathrm{K}^{+}$on development of neuronal ACh sensitivity comes from studies on muscle. Electrical activity is known to reduce the number of $\mathrm{ACh}$ receptors in muscle by decreasing the rate of receptor synthesis and accumulation (Lomo and Rosenthal, 1972; Lømo and Westgaard, 1976; Shainberg and Burstein, 1976; Reinness and Hall, 1977). The elevated $\mathrm{K}^{+}$concentration used in the present study does depolarize the neurons (Nishi and Berg, 1981b) and may 
in some respects mimic the effects of chronic electrical $\mathrm{ACh}$ receptor number are unknown, however, and the relationship between $\mathrm{ACh}$ receptor accumulation and extracellular $\mathrm{K}^{+}$concentration for muscle cells is complex (Shieh et al., 1983). Bader et al. (1982) report no differences in ACh sensitivities for ciliary ganglion neurons grown in a range of $\mathrm{K}^{+}$concentrations, but differences in the culture conditions and assay techniques used prevent a quantitative comparison with the present results.

The finding that eye extract retards development of $\alpha$-Bgt-binding sites on ciliary ganglion neurons contrasts with its effects on other neuronal properties. Previous studies have shown that eye extracts contain components that promote neuronal survival in cell culture (Adler et al., 1979) and components that enhance growth and cholinergic development of the neurons (Nishi and Berg, 1981a). The nearly 2 -fold reduction in number of $\alpha$-Bgt sites per neuron caused by eye extract would be even greater if expressed in terms of site densities (i.e., sites/ $\mu \mathrm{m}^{2}$ ) since neurons grown in $\mathrm{K}^{+}$/eye medium are larger than neurons grown in $\mathrm{K}^{+}$medium (Nishi and Berg, 1981b). With respect to other membrane components, in the present study eye extract was found to enhance development of neuronal ACh sensitivity since levels of sensitivity were significantly higher for neurons grown in $\mathrm{K}^{+}$/eye medium than for those grown in $\mathrm{K}^{+}$medium. The extract was found to have no effect on development of neuronal mechanisms for accumulating TTox, but accumulation was not saturable over the concentration ranges tested. Lack of TTox saturation has also been reported for cultures of rat cerebral cells where TTox accumulation is thought to include a component representing uptake by the cells (Yavin et al., 1981). It is possible that changes in TTox-binding capacity in the present studies went undetected because of the lack of saturability, but no effect was seen on the overall rate of TTox accumulation by the neurons.

Competition binding studies indicate that the decreased $\alpha$-Bgt binding associated with neurons grown in medium with eye extract cannot be attributed to a component in the extract that directly blocks $\alpha$-Bgt binding. Exposure to cholinergic agonists has been shown to cause down regulation of $\alpha$-Bgt-binding sites on ciliary ganglion neurons in culture (Messing, 1982). Occupation of $\alpha$-Bgt-binding sites by chronic incubation with $0.1 \mathrm{~mm}$ $d$-tubocurarine, however, does not protect against the eye extraci effect.

The function of the $\alpha$-Bgt-binding site on ciliary ganglion neurons remains unknown. Although it is unlikely to represent the synaptic $\mathrm{ACh}$ receptor on the neurons, the component may have some other synaptic function or may even represent an $\mathrm{ACh}$ receptor different from the one responsible for the nicotinic, excitatory postsynaptic potential in the ganglion. Conceivably, the component represents an inactive precursor or a degradation product of the synaptic receptor, but in this case several assumptions would be necessary to reconcile all the data. Methods for quantitating and following the fate of neuronal $\mathrm{ACh}$ receptors are likely to be necessary to resolve these questions.

\section{References}

Adler, R., K. B. Landa, M. Manthorpe, and S. Varon (1979) Cholinergic neuronotrophic factors: Intraocular distribution of trophic activity for ciliary neurons. Science 204: 14341436.

Ascher, P., W. A. Large, and H. P. Rang (1979) Studies on the mechanism of action of acetylcholine antagonists on rat parasympathetic ganglion cells. J. Physiol. (Lond.) 295: 139 170.

Bader, C. P. R., D. Bertrand, and A. C. Kato (1982) Chick ciliary ganglion in dissociated cell culture. II. Electrophysioiological properties. Dev. Biol. 94: 131-141.

Betz, H. (1981) Characterization of the $\alpha$-bungarotoxin receptor in chick embryo retina. Eur. J. Biochem. 117: 131-139.

Brehm, P., J. H. Steinbach, and Y. Kidokoro (1982) Channel open time of acetylcholine receptors on Xenopus muscle cells in dissociated cell culture. Dev. Biol. 91: 93-102.

Brown, D. A., and L. Fumagalli (1977) Dissociation of $\alpha$ bungarotoxin binding and receptor block in the rat superior cervical ganglion. Brain Res. 129: 165-168.

Bursztajn, S., and M. D. Gershon (1977) Discrimination between nicotinic receptors in vertebrate ganglia and skeletal muscle by alpha-bungarotoxin and cobra venoms. J. Physiol. (Lond.) 269: 17-31.

Carbonetto, S. T., D. M. Fambrough, and K. J. Muller (1978) Non-equivalence of $\alpha$-bungarotoxin receptors and acetylcholine receptors in chick sympathetic neurons. Proc. Natl. Acad. Sci. U. S. A. 75: 1016-1020.

Chiappinelli, V. A., J. B. Cohen, and R. E. Zigmond (1981) The effects of $\alpha$ - and $\beta$-neurotoxins from the venom of various snakes on transmission in autonomic ganglia. Brain Res. 211: 107-126.

Choi, D. W., and G. D. Fischbach (1981) GABA conductance of chick spinal cord and dorsal root ganglion neurons in cell culturc. J. Neurophysiol. 45: 605-620.

Dichter, M. A., and G. D. Fischbach (1977) The action potential of chick dorsal root ganglion neurons maintained in cell culture. J. Physiol. (Lond.) 267: 281-298.

Dimpfel, W., J. H. Neale, and E. Habermann (1975) ${ }^{125}$ I-labeled tetanus toxin as a neuronal marker in tissue cultures derived from embryonic CNA. Naunyn-Schmiedebergs Arch. Exp. Pathol. Pharmakol. 290: 329-333.

Duggan, A. W., J. G. Hall, and C. Y. Lee (1976) Alphabungarotoxin, cobra neurotoxin and excitation of Renshaw cells by acetylcholine. Brain Res. 107: 166-170.

Fambrough, D. M. (1979) Control of acetylcholine receptors in skeletal muscle. Physiol. Rev. 59: 165-227.

Fischbach, G. D., and S. M. Schuetze (1980) A post-natal decrease in acetylcholine channel open line at rat end-plates. J. Physiol. (Lond.) 303: 125-137.

Greenwood, F. C., W. M. Hunter, and J. S. Glover (1963) The preparation of ${ }^{131}$ I-labeled human growth hormone of high specific radioactivity. Biochem. J. 89: 114-123.

Jacob, M. H., and D. K. Berg (1983) The ultrastructural localization of $\alpha$-bungarotoxin binding sites in relation to synapses on chick ciliary ganglion neurons. J. Neurosci. 3: 260271.

Ko, C. P., H. Burton, and R. P. Bunge (1976) Synaptic transmission between rat spinal cord explants and dissociated superior cervical ganglion neurons in tissue culture. Brain Res. 117: 437-460.

Kouvelas, E. D., M. A. Dichter, and L. A. Greene (1978) Chick sympathetic neurons develop receptors for $\alpha$-bungarotoxin in vitro, but the toxin does not block nicotinic receptors. Brain Res. 154: 83-93.

Kullberg, R. W., P. Brehm, and J. H. Steinbach (1981) Non- 
junctional acetylcholine receptor channel open time decreases during development of Xenopus muscle. Nature 289: 411-413.

Landmesser, L., and G. Pilar (1978) Interactions between neurons and their targets during in vivo synaptogenesis. Fed. Proc. 37: 2016-2022.

Lømo, T., and J. Rosenthal (1972) Control of ACh sensitivity by muscle activity in the rat. J. Physiol. (Lond.) 221: 493513.

Lømo, T., and R. H. Westgaard (1976) Control of ACh sensitivity in rat muscle fibres. Cold Spring Harbor Symp. Quant. Biol. 40: 263-274.

Margiotta, J. F., and D. K. Berg (1982) Functional synapses are established between ciliary ganglion neurons in dissociated cell culture. Nature 296: 152-154.

Marshall, L. M. (1981) Synaptic localization of $\alpha$-bungarotoxin binding which blocks nicotinic transmission at frog sympathetic neurons. Proc. Natl. Acad. Sci. U. S. A. 78: 1948-1952.

Martin, A. R., and G. Pilar (1963a) Dual mode of synaptic transmission in the avian ciliary ganglion. J. Physiol. (Lond.) 163: 443-463.

Martin, A. R., and G. Pilar (1963b) Transmission through the ciliary ganglion of the chick. J. Physiol. (Lond.) 168: 464475.

Mellanby, J., and J. Green (1981) How does tetanus toxin act? Neuroscience 6: 281-300.

Messing, A. (1982) Cholinergic agonist induced down regulation of neuronal $\alpha$-bungarotoxin receptors. Brain Res. 232: 479484 .

Mirsky, R., L. M. B. Wendon, P. Black, C. Stolkin, and D. Bray (1978) Tetanus toxin: A cell surface marker for neurones in culture. Brain Res. 148: 251-259.

Morley, B. J., and G. E. Kemp (1981) Characterization of a putative nicotinic acetylcholine receptor in mammalian brain. Brain Res. Rev. 3: 81-104.

Nishi, R., and D. K. Berg (1981a) Two components from eye tissue that differentially stimulate the growth and development of ciliary ganglion neurons in cell culture. J. Neurosci. 1: 505-513.

Nishi, R., and D. K. Berg (1981b) Effects of high $\mathrm{K}^{+}$concentrations on the growth and development of ciliary ganglion neurons in cell culture. Dev. Biol. 87: 301-307.

Nurse, C. A., and P. H. O'Lague (1975) Formation of cholinergic synapses between dissociated sympathetic neurons and skeletal myotubes of the rat in cell culture. Proc. Natl. Acad. Sci. U. S. A. 72: 1955-1959.

O'Lague, P. H., D. D. Potter, and E. J. Furshpan (1978) Studies on rat sympathetic neurons developing in cell culture. I.
Growth characteristics and electrophysiological properties. Dev. Biol. 67: 384-403.

Oswald, R. E., and J. A. Freeman (1981) Alpha-bungarotoxin binding and central nervous system nicotinic acetylcholine receptors. Neuroscience $6: 1-14$.

Patrick, J., and W. B. Stallcup (1977a) $\alpha$-Bungarotoxin binding and cholinergic receptor function on a rat sympathetic nerve line. J. Biol. Chem. 252: 8629-8633.

Patrick, J., and W. B. Stallcup (1977b) Immunological distinction between acetylcholine receptor and the $\alpha$-bungarotoxin binding component on sympathetic neurons. Proc. Natl. Acad. Sci. U. S. A. 74: 4689-4692.

Ravdin, P. M., and D. K. Berg (1979) Inhibition of neuronal acetylcholine sensitivity by $\alpha$-toxins from Bungarus multicinctus venom. Proc. Natl. Acad. Sci. U. S. A. 76: 2072-2076.

Ravdin, P. M., R. M. Nitkin, and D. K. Berg (1981) Internalization of $\alpha$-bungarotoxin on neurons induced by a neurotoxin that blocks neuronal acetylcholine sensitivity. J. Neurosci. 1: 849-861.

Reinness, C. G., and Z. W. Hall (1977) Electrical stimulation of denervated muscles reduces incorporation of methionine into the ACh receptor. Nature 268: 655-657.

Sakmann, B., and H. R. Brenner (1978) Change in synaptic channel gating during neuromuscular development. Nature 276: 401-402.

Shainberg, A., and M. Burstein (1976) Decrease of acctylcholine receptor synthesis in muscle cultures by electrical stimulation. Nature 264: 368-369.

Shieh, B. -H., L. Tezzementi, and J. Schmidt (1983) Extracellular potassium and the regulation of acetylcholine receptor synthesis in embryonic chick muscle cells. Brain Res. 263: $259-265$.

Smith, M. A., J. F. Margiotta, and D. K. Berg (1982) Differences in the regulation of acetylcholine sensitivity and $\alpha$-bungarotoxin binding on chick ciliary ganglion neurons in cell culture. Soc. Neurosci. Abstr. 8: 799.

Syapin, P. J., P. M. Salvaterra, and J. K. Engelhardt (1982) Neuronal-like features of TE671 cells: Presence of a functional nicotinic cholinergic receptor. Brain Res. 231: 365377.

Vogel, A., A. J. Sytkowski, and M. W. Nirenberg (1972) Acetylcholine receptors of muscle grown in vitro. Proc. Natl. Acad. Sci. U. S. A. 69: 3180-3184.

Yavin, E., Z. Yavin, W. H. Habig, M. C. Hardegree, and L. D. Kohn (1981) Tetanus toxin association with developing neuronal cell cultures. Kinetic parameters and evidence for ganglioside-mediated internalization. J. Biol. Chem. 256: 70147022 . 